\title{
Transient-False Method for Solving System of Nonlinear Partial Differential Equations
}

\author{
Dr. Ali Khalaf Hussain \\ Wassit university/college of Education \\ Department of Mathematics department
}

\begin{abstract}
In this paper we study the false transient method to solve and transform a system of non-linear partial differential equations which can be solved using finitedifference method and give some problems which have a good results compared with the exact solution, whereas this method was used to transform the nonlinear partial differential equation to a linear partial differential equation which can be solved by using the alternating-direction implicit method after using the ADI method. The system of linear algebraic equations could be obtained and can be solved by using MATLAB.
\end{abstract}

Keyword: Non-Linear, Alternating-direction implicit method and MATHLAB software.

الخلاصة

في هذا البحث قمنا بدراسة طريقة Transient-False لحل وتحويل نظام المعدلات غير الخطية الى

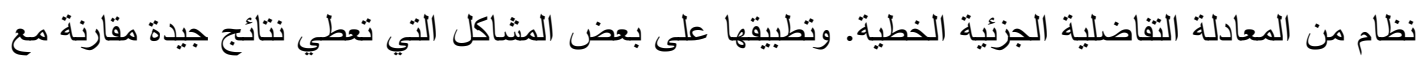
الحل التحليلي. وبواسطة هذه الطريقة يتم تحويل نظام من المعادلات التفاضلية الجزئية غير الخطية لنظام الخطية التي يمكن حلها باستخدام اساليب وطرق رياضية مثل طريقة الفروق المنتهية. في حين نم استخدام هذا الأسلوب لتحويل المعادلة التفاضلية الجزئية غير الخطية إلى المعادلة التفاضلية الجزئية الخطية التي في فئي يمكن حلها باستخدام الأسلوب بالتتاوب الاتجاه الضمني بعد باستخدام طريقة ADI وان نظام المعادلات

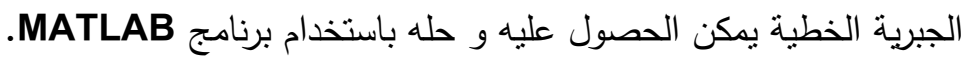




\section{1- Introduction}

"It is fair to say that only the simplest physical systems can be modeled by ordinary differential equations, whereas most problems in fluid mechanics elasticity, heat transfer, electromagnetic theory, quantum mechanics, and other areas of physics lead to partial differential equations. Indeed, the range of application of the latter is enormous, compared to that of ordinary differential equations" [Hornbeck R.,1975] and [Kreysizig E., 2004].

Today's engineering and science students and researchers routinely confront problems in mathematical modeling involving solution techniques for differential equations such as Ibragimov N. H. in [Al-Sharwany F.,2009] and [Smith G.,1978]. Engineering science and many branches of applied mathematics (e.g., in fluid dynamics, boundary layer theory, heat transfer) [Juneyub L. and Leslie G.,1977] and [Kubiček M. and Hlavaek V.,1983], all of them give many partial differential equations. Only a few of them can be solved by analytical methods. So, in most cases, one can go in, for numerical methods of approximate solution. There are many methods to solve partial differential equations, such as the collocation method [Kantorovich L., and AKilov1969] and [Evans G., Blakledge J. and YardleyP.,2001],Monte Carlo methods, methods of lines [Ames W.,1977] and [Fred B. and Jone A.,1973].

In this work, the false transient method "was used for solving some systems of nonlinear partial differential equations, and by this method the system of nonlinear partial differential equations transformed to a system of linear partial differential equations which can be solved using finite-difference method and give some problems which have a good results compared with the exact solution, whereas this method was used to transform the nonlinear partial differential equation to a linear partial differential equation which can be solved by using the alternating-direction implicit method after using the ADI method" [Al- Amery M., 2009]. The system of linear algebraic equations could be obtained and can be solved by using MATLAB computer software. 


\section{2- Derivation of the equation}

\subsection{The False Transient Equation}

"If the steady-state solution to partial differential equations exists and is both stable and unique, the false transient equations leads to the final steady-state solution which is also the solution of the original nonlinear boundary value problem".

The steady-state solution of a nonlinear boundary value problem may be found by solving directly the steady state equation or by solving the transient equation.

An element $y *$ for which:

$$
F(y *)=0 .
$$

"is called the steady-state solution" of

$$
\frac{d y}{d t}=F(y)
$$

For stable steady-state, one may get:

$$
y *=\lim _{t \rightarrow \infty} y(t) \ldots \ldots \ldots
$$

where $y(t)$ is a solution of the false transient equation (2) subject to an appropriate initial conditions:

$$
y(0)=y_{0}
$$

the effectiveness of the calculation on the steady-state $y *$ may be estimated according to the rate of the decay of the transient term, i.e., the time variable $t$ for which

$$
\|y(t)-y *\|<\epsilon_{1}
$$

or

$$
\|F(y(t))\|<\epsilon_{2}
$$


where $\epsilon_{1}$ and $\epsilon_{2}$ are small positive numbers, can be considered as a criterion of effectiveness. To enhance the rate of convergence to the steady-state solution the "accumulation" term can be modified

$$
A \frac{\mathrm{dy}}{\mathrm{dt}}=F(y)
$$

where $\mathrm{A}$ is an operator. It is obvious that the steady-state solution of equation (7), $\mathrm{y}^{*}$ is also the solution of equation (2). However, the steady-state solution $\mathrm{y}^{*}$ may be unstable with respect to equation (2) but its stability [Smith, 1978] is guaranteed for equation (7).

For instance, $A=-F^{\prime}(y)$ a continuous version of the modified Newton method result. Here $y_{0}$ is an appropriate initial approximation. Consider, for example, the operator $\mathrm{F}$ in the form:

$$
F(y)=\frac{\mathrm{d}^{2} \mathrm{y}}{\mathrm{dx}^{2}}-f\left\lceil\mathrm{x}, \mathrm{y}(\mathrm{x}), \frac{\mathrm{d} \mathrm{y}}{\mathrm{dx}}\right\rceil=0
$$

subject to homogeneous boundary conditions:

$$
y(0)=0, \quad y(1)=0, \quad x(0)=0, \quad x(1)=1
$$

"After adding the fictitious accumulation term the ordinary different equation, equation(8), becomes partial differential equation”.

$$
\frac{\partial y(x, t)}{\partial t}=\frac{\partial \mathrm{y}^{2}(\mathrm{x}, \mathrm{t})}{\partial \mathrm{x}^{2}}-f\left[\mathrm{x}, \mathrm{y}(\mathrm{x}, \mathrm{t}), \frac{\partial \mathrm{y}(\mathrm{x}, \mathrm{t})}{\partial \mathrm{x}}\right]
$$

Subject to the boundary condition (9). The initial condition can be chosen arbitrarily, however, it should be physically consistent with the particular equation:

$$
y(x, 0)=y(x)
$$


There are number of numerical methods for finding the solution of equation (10).

The object is to show the implicit finite-difference method to provide solution of the false transient equations.

The method of false transient is illustrated by the following example:

\section{3-Results and Discussion}

In the previous section, the false transient method was discussed for solving system of nonlinear ordinary differential equations.

Now, in this section this method will be generalized to solve systems of nonlinear second order partial differential equations of the form:

$$
\begin{aligned}
& F_{1}(u, v)=\frac{\partial^{2} \mathrm{u}}{\partial \mathrm{x}^{2}}-f_{1}\left(x, t, u(x, t), v(x, t), \frac{\partial \mathrm{u}}{\partial \mathrm{x}}, \frac{\partial \mathrm{v}}{\partial \mathrm{x}}, \frac{\partial \mathrm{u}}{\partial \mathrm{t}}, \frac{\partial \mathrm{v}}{\partial \mathrm{t}}\right) \ldots \ldots . . \\
& F_{2}(u, v)=\frac{\partial^{2} \mathrm{v}}{\partial \mathrm{x}^{2}}-f_{2}\left(x, t, u(x, t), v(x, t), \frac{\partial \mathrm{u}}{\partial \mathrm{x}}, \frac{\partial \mathrm{v}}{\partial \mathrm{x}}, \frac{\partial \mathrm{u}}{\partial \mathrm{t}}, \frac{\partial \mathrm{v}}{\partial \mathrm{t}}\right) \ldots \ldots . .
\end{aligned}
$$

with the initial conditions:

$$
\left.\begin{array}{c}
\mathrm{u}(\mathrm{x}, 0)=k_{1}(\mathrm{x}) \quad, \mathrm{a} \leq \mathrm{x} \leq \mathrm{b} \\
v(x, 0)=k_{2}(\mathrm{x})
\end{array}\right\}
$$

and the boundary conditions: $\phi_{1}$

$$
\left.\begin{array}{c}
u(a, t)=\phi_{1}(\mathrm{t}) \\
u(b, t)=\phi_{2}(\mathrm{t}), 0 \leq \mathrm{t}<\infty \\
v(a, t)=\psi_{1}(\mathrm{t}) \\
v(b, t)=\psi_{2}(\mathrm{t})
\end{array}\right\} \ldots \ldots \ldots . .
$$

where $\phi_{1}(t), \phi_{2}(t), \psi_{1}(t), \psi_{2}(t), k_{1}(t)$ and $k_{2}(t)$ are continuous functions. Also the functions $f_{1}$ and $f_{2}$ are supposed to be continuously differentiable with respect to 
$\mathrm{u}, \mathrm{v}, \mathrm{u}_{\mathrm{x}}, \mathrm{v}_{\mathrm{x}}, \mathrm{u}_{\mathrm{t}}, \mathrm{v}_{\mathrm{t}}$ and $\mathrm{F}_{1}, \mathrm{~F}_{2}$ are the mappings defined from the space $\mathrm{U}$. The false transient method is based on adding the false-transient derivative, after adding false transient term, equations (30) and (31) becomes a set of linear partial differential equations:

$$
\frac{\partial \mathrm{u}(\mathrm{x}, \mathrm{t})}{\partial \mathrm{t}}=\frac{\partial^{2} \mathrm{u}(\mathrm{x}, \mathrm{t})}{\partial \mathrm{x}^{2}}-F_{1}\left(x, t, u(x, t), v(x, t), \frac{\partial \mathrm{u}}{\partial \mathrm{x}}, \frac{\partial \mathrm{v}}{\partial \mathrm{x}}, \frac{\partial \mathrm{u}}{\partial \mathrm{t}}, \frac{\partial \mathrm{v}}{\partial \mathrm{t}}\right) \ldots \ldots
$$

$$
\frac{\partial \mathrm{v}(\mathrm{x}, \mathrm{t})}{\partial \mathrm{t}}=\frac{\partial^{2} \mathrm{v}(\mathrm{x}, \mathrm{t})}{\partial \mathrm{x}^{2}}-F_{2}\left(x, t, u(x, t), v(x, t), \frac{\partial \mathrm{u}}{\partial \mathrm{x}}, \frac{\partial \mathrm{v}}{\partial \mathrm{x}}, \frac{\partial \mathrm{u}}{\partial \mathrm{t}}, \frac{\partial \mathrm{v}}{\partial \mathrm{t}}\right) \ldots \ldots \ldots
$$

subject to the initial conditions:

$\mathrm{u}(\mathrm{x}, 0)=\mathrm{k}_{1}(\mathrm{x}) \quad, \mathrm{a} \leq \mathrm{x} \leq \mathrm{b}$

$\mathrm{v}(\mathrm{x}, 0)=\mathrm{k}_{2}(\mathrm{x})$

and with the boundary conditions of the form:

$\mathrm{u}(\mathrm{a}, \mathrm{t})=\phi_{1}(\mathrm{t})$

$\mathrm{u}(\mathrm{b}, \mathrm{t})=\phi_{2}(\mathrm{t})$

, $0 \leq \mathrm{t}<\infty$

$\mathrm{v}(\mathrm{a}, \mathrm{t})=\psi_{1}(\mathrm{t})$

$\mathrm{v}(\mathrm{b}, \mathrm{t})=\psi_{2}(\mathrm{t})$

After that, apply the finite-difference method by substituting equations (2.65), (2.66) and (2.68) in [ Al- Amery M.(2009)] on the above equations. The resulting system of linear algebraic equations is obtained which can be solved using MATLAB computer software. 
The generalization of the false transient method are illustrated by the following example:

$0 \leq t<\infty$

Example:

Consider the boundary value problems:

$$
\begin{aligned}
& u_{x x}+u_{x} v-2 x=0 \\
& v_{x x}+v_{x} u-2 x=0
\end{aligned}
$$

subject to the initial-boundary conditions:

$$
\left.\begin{array}{c}
u(x, 0)=x \\
0 \leq x \leq 1 \\
v(x, 0)=2 x \\
u(0, t)=0 \\
u(1, t)=1 \\
v(0, t)=0 \\
v(1, t)=2
\end{array}\right\}
$$

The exact solution related to this problem is given by $u(x, t)=x$ and $v(x, t)=2 x$.

The false transient equations may be written in the form:

$\mathrm{u}_{\mathrm{t}}=\mathrm{u}_{\mathrm{xx}}+\mathrm{u}_{\mathrm{x}} \mathrm{v}-2 \mathrm{x}$

$\mathrm{v}_{\mathrm{t}}=\mathrm{v}_{\mathrm{xx}}+\mathrm{v}_{\mathrm{x}} \mathrm{u}-\mathrm{x}$

subject to the initial-boundary conditions

$(\mathrm{t}>0)$ : 


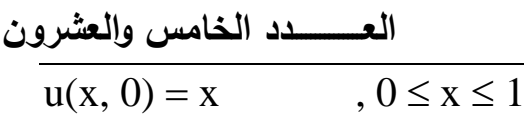

$$
\begin{aligned}
& \mathrm{v}(\mathrm{x}, 0)=0 \\
& \mathrm{u}(0, \mathrm{y})=0 \\
& \mathrm{u}(1, \mathrm{y})=1 \quad, 0 \leq \mathrm{y} \leq 1 . .(44) \\
& \mathrm{v}(0, \mathrm{y})=0 \\
& \mathrm{v}(1, \mathrm{y})=2 \\
& \text { by using the finite difference method (Crank-Nicolson implicit method) } \\
& (\mathrm{h}=0.2, \mathrm{k}=0.02) \text {, one can get: } \\
& \frac{u_{i, j+1}-u_{i, j}}{k}=\left\lceil\left[\frac{u_{i+1, j}-2 u_{i, j}+u_{i-1, j}+u_{i+1, j+1}-2 u_{i, j+1}+u_{i-1, j+1}}{h^{2}}\right\rfloor+\frac{u_{i+1, j}-u_{i, j}}{h} v_{i, j}-2 x_{i}\right. \\
& \frac{v_{i, j+1}-v_{i, j}}{k}=\frac{1}{2}\left\lceil\frac{v_{i+1, j}-2 v_{i, j}+v_{i-1, j}+v_{i+1, j+1}-2 v_{i, j+1}+v_{i-1, j+1}}{h^{2}}\right\rfloor+\frac{v_{i+1, j}-v_{i, j}}{h} u_{i, j}-2 x_{i} .
\end{aligned}
$$

After some computations, the study has:

$$
\begin{aligned}
& \left.15 u_{i, j+1}-5 u_{i, j}-2.5 u_{i+1, j}-2.5 u_{i-1, j}-2.5 u_{i+1, j+1}-2.5 u_{i-1, j+1}-\left[\left(u_{i+1, j}-u_{i, j}\right) v_{i, j}\right)\right]+0.4 x_{i} \\
& =0 \\
& \left.15 v_{i, j+1}-5 v_{i, j}-2.5 v_{i+1, j}-2.5 v_{i-1, j}-2.5 v_{i+1, j+1}-2.5 v_{i-1, j+1}-\left[\left(v_{i+1, j}-v_{i, j}\right) u_{i, j}\right)\right]+0.4 x_{i} \\
& =0
\end{aligned}
$$


Moreover:

$\mathrm{u}_{0,0}=0$

$\mathrm{u}_{1,0}=0.2, \mathrm{u}_{2,0}=0.4, \mathrm{u}_{3,0}=0.6, \mathrm{u}_{4,0}=0.8$

$\mathrm{v}_{0,0}=0$

$\mathrm{v}_{1,0}=0.4, \mathrm{v}_{2,0}=0.8, \mathrm{v}_{3,0}=1.2, \mathrm{v}_{4,0}=1.6$

Now, discretizing over all $\mathrm{i}=1,2,3,4, \mathrm{j}=0$, we have for $\mathrm{i}=1, \mathrm{j}=0$ :

$\left.15 \mathrm{u}_{1,1}-5 \mathrm{u}_{1,0}-2.5 \mathrm{u}_{2,0}-2.5 \mathrm{u}_{0,0}-2.5 \mathrm{u}_{2,1}-2.5 \mathrm{u}_{0,1}-\left[\left(\mathrm{u}_{2,0}-\mathrm{u}_{1,0}\right) \mathrm{v}_{1,0}\right)\right]+0.4(0.2)=0$

$15 \mathrm{u}_{1,1}-2.5 \mathrm{u}_{2,1}=2$

by the same procedure at $\mathrm{i}=2,3,4$ :

$-2.5 \mathrm{u}_{1,1}+15 \mathrm{u}_{2,1}-2.5 \mathrm{u}_{3,1}=4$

$-2.5 \mathrm{u}_{2,1}+15 \mathrm{u}_{3,1}-2.5 \mathrm{u}_{4,1}=6$

$-2.5 \mathrm{u}_{3,1}+15 \mathrm{u}_{4,1}=10.5$

$15 \mathrm{v}_{1,1}-2.5 \mathrm{v}_{2,1}=4$

$-2.5 \mathrm{v}_{1,1}+15 \mathrm{v}_{2,1}-2.5 \mathrm{v}_{3,1}=8$

$-2.5 \mathrm{v}_{2,1}+15 \mathrm{v}_{3,1}-2.5 \mathrm{v}_{4,1}=12$

$-2.5 \mathrm{v}_{3,1}+15 \mathrm{v}_{4,1}=20$

The resulting set of linear algebraic equations can be easily solved by direct methods after transforming this system to the matrix form as: 


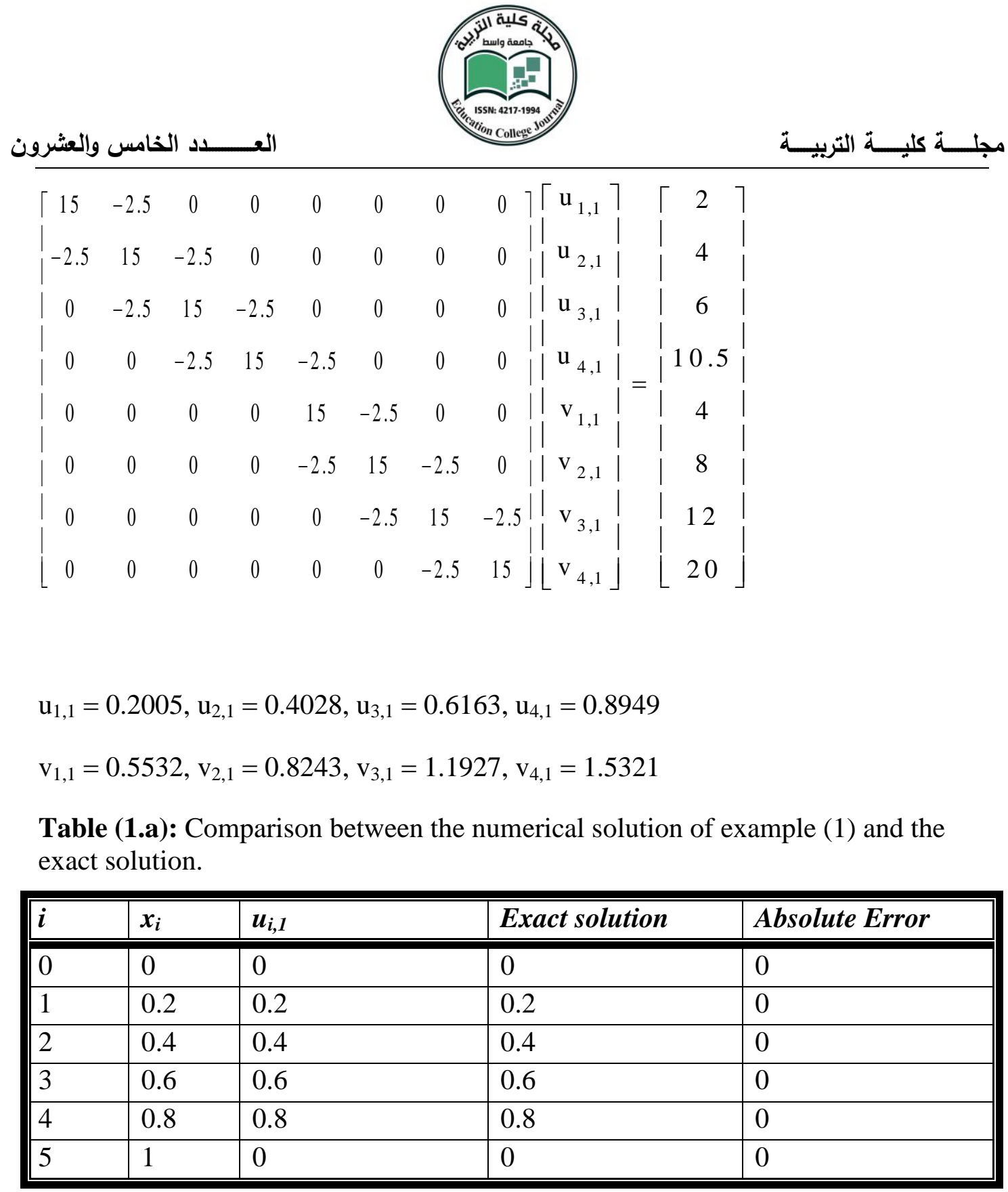




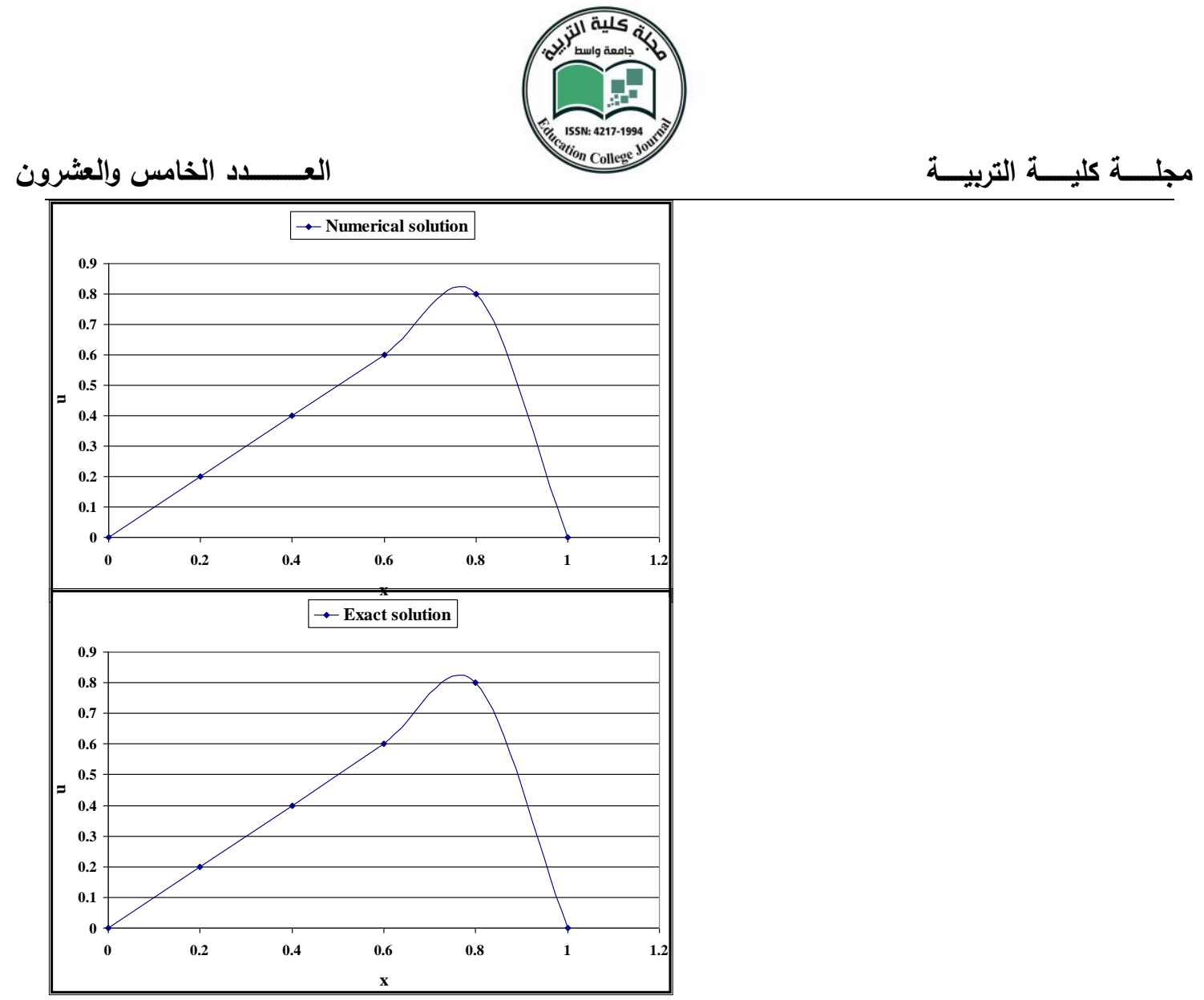

Fig.(1.a) Comparison between the numerical solution of example (1) and the exact solution.

Table (1.b): Comparison between the numerical solution of example (1) and the exact solution.

\begin{tabular}{||l|l|l|l|l|}
\hline $\boldsymbol{i}$ & $\boldsymbol{x}_{\boldsymbol{i}}$ & $\boldsymbol{v}_{\boldsymbol{i}, \boldsymbol{I}}$ & Exact solution & Absolute Error \\
\hline \hline 0 & 0 & 0 & 0 & 0 \\
\hline 1 & 0.2 & 0.4039 & 0.4 & 0.0039 \\
\hline 2 & 0.4 & 0.8076 & 0.8 & 0.0076 \\
\hline 3 & 0.6 & 1.2106 & 1.2 & 0.0106 \\
\hline 4 & 0.8 & 1.5906 & 1.6 & 0.0094 \\
\hline 5 & 1 & 0 & 0 & 0 \\
\hline & & & & \\
\hline \hline
\end{tabular}



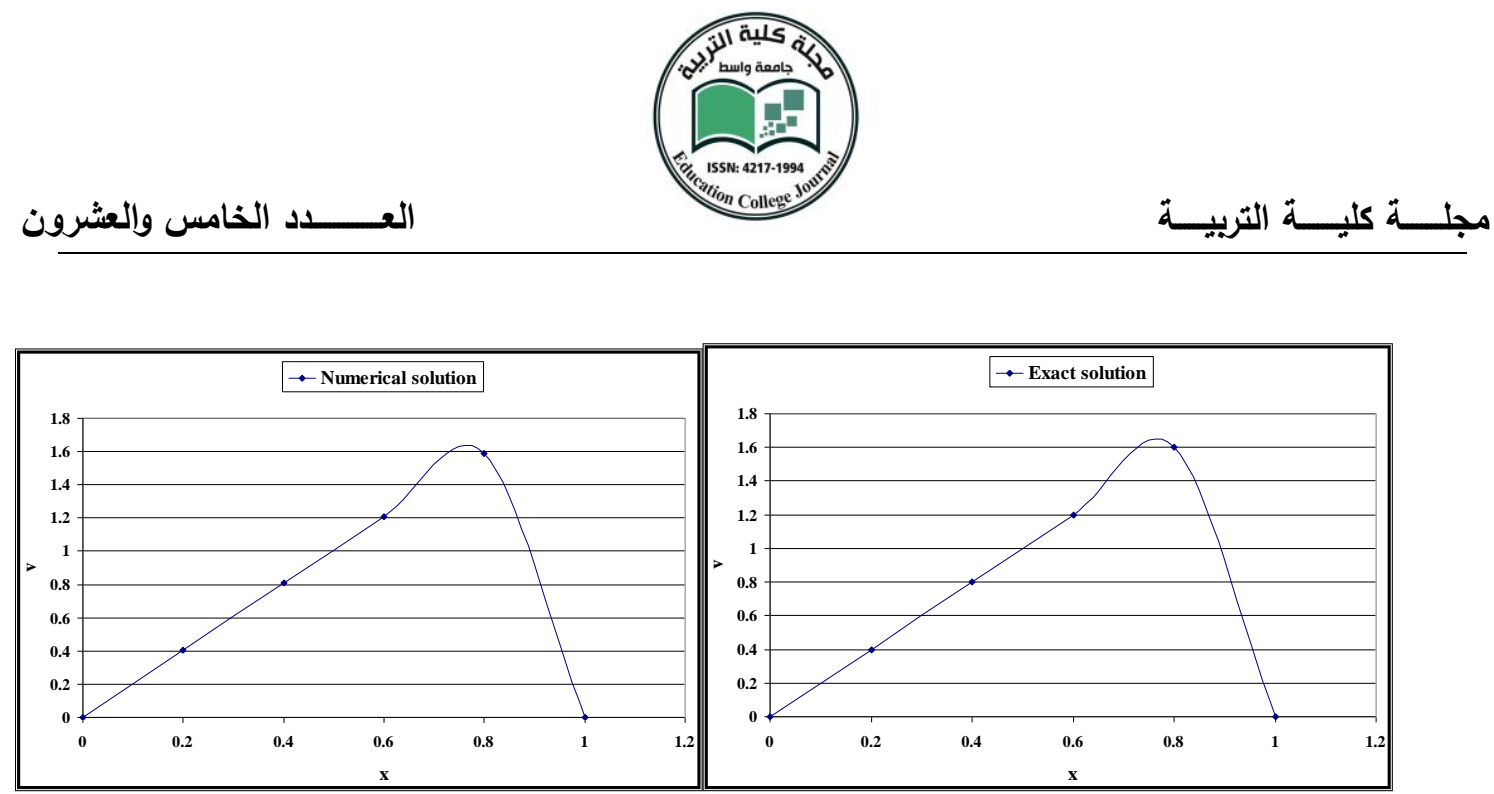

Fig.(1.b) Comparison between the numerical solution of example (1) and the exact solution. 
3-Conclusion and recommendation:

1. The false transient method can be adopted to convection nonlinear problems with split boundary conditions (heat exchangers, tabular, reactors with counter, current cooling, etc.).

2. The finite difference method for solving nonlinear differential equations gives less accurate results from the results obtained by Newton-Kantrovich method.

3. Many problems cannot be solved by analytic methods. Practically, all nonlinear PDE's must be solved by numerical methods, and in fact, most realistic methods in physics, chemistry, biology, and so forth are nonlinear in nature. 


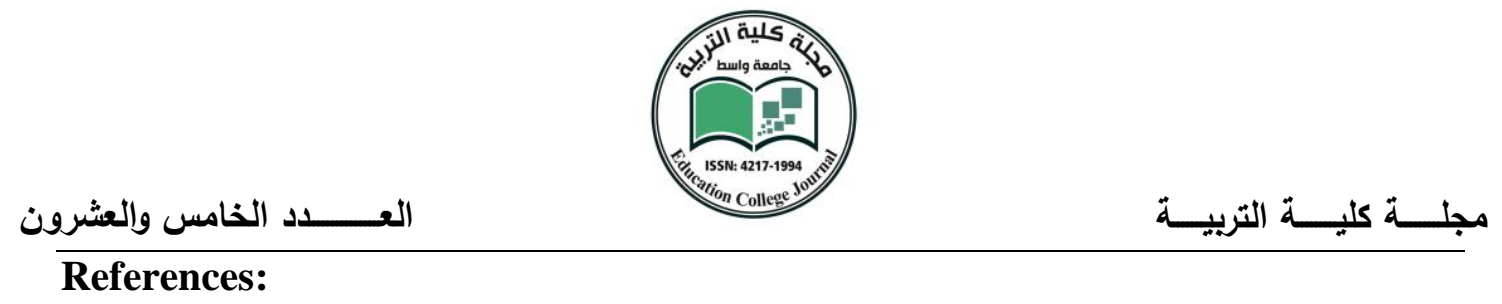

Al- Amery M.(2009), " Numerical Treatment for Solving System of Nonlinear Differential Equations" .

Al-Sharwany F.,(2009), "Some Exact Solution for Spherically Symmetric Four-

Fold of Class One", M.Sc. Thesis, University of Al- Mustensiriah.

Ames W.,(1977), "Numerical Methods for Partial Differential Equation",

Academic Press, New York, San Francisco.

Evans G., Blakledge J. and Yardley P.,(2001), "Numerical Methods for Partial Differential Equations", Springer-Verelag, London Limited.

Fred B. and Jone A.,(1973), "Ordinary Differential Equations", University of Wisconsin.

Hornbeck R.,(1975), " Numerical Methods" ,Quantum, Inc.

Juneyub L. and Leslie G.,(1977), "A Fast Adaptive Numerical Method for Stiff Two-Point Boundary Value Problems", SIAM J. Sci. Comput., Vol.18,PP.403429.

Kantorovich L., and A Kilov,(1969), "Functional Analysis in Normed Space" , Pergamon Press, New York .

Kreysizig E.,(2004), "Advanced Engineering Mathematics", Ohio Star University, Columbus, Ohio.

Kubiček M. and Hlavaek V.,(1983), "The Numerical Solution of Nonlinear Boundary Value Problems with Applications", Prentic-Hall, Inc.

Smith G.,(1978), "Numerical Solution Partial Differential Equation ", Oxford University Press, Walton Street. 